\title{
A meta-analysis of depressive symptoms among Ethiopian prisoners and a narrative description of its associated factors: a country based systematic review and meta- analysis study
}

\author{
Mogesie Necho* ${ }^{*}$, Asmare Belete, Mekonnen Tsehay and Yosef Zenebe
}

\begin{abstract}
Background: The burden of depression in prisoners is increasing and factors such as co-existence of medical illness, lack of social support and longer duration of sentences are contributing to it. However, no pooled evidence on the magnitude and factors of depression in prisoners existed in Ethiopia. The current meta-analysis was therefore aimed to have aggregate evidence on the magnitude and factors of depression in prisoners of Ethiopia.

Methods: A search of databases on PubMed, Scopus, and EMBASE was carried out systematically. Besides, grey literature sources were extensively investigated. Moreover, the reference lists of the articles selected were searched. Random effects and quality-effects models were used to describe the pooled prevalence of depressive symptoms with $95 \% \mathrm{Cl}$. We also detect heterogeneity between studies using Cochran's Q- statistic and the Higgs I ${ }^{2}$ test. A sensitivity analysis was also implemented. Publication bias was checked with Egger's test and funnel plots visually.

Results: Among 232 papers identified through the specified database searches only 17 full-text articles were assessed for eligibility and only nine (9) studies fulfilled the prespecified criteria and incorporated in the final metaanalysis. The pooled prevalence of Depressive symptoms among prisoners was $53.40 \%(95 \% \mathrm{Cl}$ : 41.33, 65.46). The pooled prevalence of Depressive symptoms in prisoners was $41.9 \%$ in Southwest Ethiopia, $44.43 \%$ in North West of Ethiopia, 59.05\% in Addis Ababa, and 72.7\% Southern Ethiopia. Besides, the pooled Depression symptoms prevalence among prisoners was 51.24\% as measured with PHQ-9 and 56.15\% with BDI-II. Besides, studies that utilized a relatively large sample size $(\geq 350)$ yields a smaller pooled prevalence of Depression symptoms, 51.93\% than those which utilized smaller sample sizes $(<350) ; 54.13 \%$.

Conclusion: The pooled magnitude of depression in prisoner's population is very high, $53.40 \%$. This pooled effect size for the Depression symptoms was significantly higher in the southern region of the country than in the southwest region. Besides, the pooled prevalence was significantly higher as measured by the BDI-II tool than by PHQ-9. Also, studies that utilized a larger sample size provided a significantly lower pooled magnitude of symptoms of depression than studies that utilized a smaller sample size.
\end{abstract}

Keywords: Meta-analysis, Depression, Ethiopia, Prisoners

\footnotetext{
* Correspondence: nechomoges2014@gmail.com

Department of Psychiatry, Wollo University, College of Medicine and Health

Sciences, Dessie, Ethiopia
}

(c) The Author(s). 2020 Open Access This article is licensed under a Creative Commons Attribution 4.0 International License, which permits use, sharing, adaptation, distribution and reproduction in any medium or format, as long as you give appropriate credit to the original author(s) and the source, provide a link to the Creative Commons licence, and indicate if changes were made. The images or other third party material in this article are included in the article's Creative Commons licence, unless indicated otherwise in a credit line to the material. If material is not included in the article's Creative Commons licence and your intended use is not permitted by statutory regulation or exceeds the permitted use, you will need to obtain permission directly from the copyright holder. To view a copy of this licence, visit http://creativecommons.org/licenses/by/4.0/ The Creative Commons Public Domain Dedication waiver (http://creativecommons.org/publicdomain/zero/1.0/) applies to the data made available in this article, unless otherwise stated in a credit line to the data. 


\section{Background}

Ethiopia has huge number of prisons both at the federal and regional levels. Three of the Ethiopian prisons namely, Kality prison, Diredawa prison, and Shewarobit prison are under the administration of the federal government. Mostly the federal prisons are used basically to handle serious crimes. Kality Prison; synonymously called Kilinto Prison is among the federal prisons and located in Addis Ababa and serves as the main prison of the country where the most severe form of crime that needs a long duration of sentences is handled there. Besides, around 9 regional prisons are found in the 9 regions of the country [1]. Normally prisoners in Ethiopia are involved in skill-building activities while they are in prison which is essential for their future life as they are mostly in the productive age group.

In 2001 World Health Organization (WHO) projected that depression will account for the second leading burden of diseases globally in 2020 [2]. More than 66 million people are affected by depression in the world as reported from the world health organization in which $85 \%$ reside in countries with low and middle income [3]. Mental illness is also highly prevalent in correctional institutions [4] with the magnitude of severe psychiatric problems up to 5-10 times higher among prisoners as compared to the general population [5]. WHO reported that $11 \%$ of world-wide prisoners were affected by mental health problems [6]. In prisons from Europe, the magnitude of psychotic disorders was 5\%, depression and anxiety disorders were $25 \%$, and disorders of substance use was approximately $40 \%$ [7].

A systematic review and meta-analysis of 62 studies in 12 countries showed that 3.7 and $65 \%$ of male inmates were with psychotic illnesses and a personality disorder respectively whereas 4 and $42 \%$ of female prisoners had a psychotic illness and a personality disorder respectively [8]. Another meta-analysis on 109 studies from 24 countries and a total of 33,588 inmates revealed that the pooled magnitude of psychosis was $3.6 \%$ in male inmates and $3.9 \%$ in female inmates [8]. In Ethiopia, too mental illness is common in prisoners with anxiety to be $36.1 \%$ in Amhara [9], suicidal behavior's $23.2 \%$ in Jimma [10] and common mental disorders $58.4 \%$ in Addis Ababa [11] and substance use disorders,55.9\% [12].

Depression is prevalent in prisoners [13]. A review and meta-analysis study in Iran on a total of 1708 prisoners and 12 articles obtained a pooled magnitude of depression to be $42 \%$; $44 \%$ of male prisoners and $33 \%$ of female prisoners [14]. Another meta-analysis reports indicated that $10 \%$ of male and $12 \%$ of female prisoners [8] and $10.2 \%$ of male and $14.1 \%$ of female prisoners [8] had depression. Other preceding studies publicized that depression in prisoners was $24 \%$ in France [5], 19.2\% in Norway [15], 40.7\% in Malaysia [16], 8.1\% in Chile [17],
85\% in Pakistan [18], and 35\% of convicted inmates and $30.1 \%$ of prisoners awaiting trial in Nigeria [19]. Studies on prisoners of Ethiopia showed that the magnitude of depression in prisoner's population ranges between 41.9 and $89 \%[10,20-26]$ higher than the pooled estimate of depression obtained by a meta-analysis study among the general population; 11\% [27]. Regional distribution of depression in Ethiopian prisoners can be described as ranging from 43.8 to $45.5 \%$ in Amhara region [20, 22, 25], 56.4 to $89 \%$ in southern Ethiopia [21, 24], 51.6 to $66.5 \%$ in Addis Ababa $[26,28]$ and $41.9 \%$ in Oromia region [10, 23].

A national health survey on depression in Ethiopia identified $9.1 \%$ of the population to be affected by depression [29]. Moreover, A review and meta-analysis of depression in the Ethiopian community found a pooled depression prevalence of $20.5 \%$ [30] which was relatively high and implies a huge public health concern of the problem. However, only a few people with depression were found to have access to treatment and this high unmet need for depression might also contribute to criminal involvement.

A review and meta-analysis of 14 studies identified multiple modifiable factors (environmental, family support and psychological factors) as well as non-modifiable factors (social, demographic, individual and biological factors) as contributing to depression in prisoners [31]. Factors contributing to a variation of prevalence between studies in prisoners were gender, instruments used and offense categories (violent offenses) [14]. Identified determinants for depression in prisoners were female sex $[8,32-36]$, old age $[37,38]$, multiple incarcerations and work burden inside the prison $[8,39,40]$ and history of mental illness $[40,41]$ from countries abroad whereas in the context of Ethiopia co-morbid medical illness [21, $23,25,26]$, longer duration of a sentence $[20,25,26]$, poor social support [22, 23], family history of mental illness, previous incarceration and lifetime alcohol use [23], a suicidal attempt and ever-faced a stressful event [25] were mentioned so far as associated with depression in a correctional setting.

Depression is accounted for as the burden of the third most common disease in Ethiopia [42]. It affects multiple domains of life such as increased involvement in substance use [43], suicide risk [44-46], elevated risk for diseases of metabolic syndrome $[47,48]$ and advances in the occurrence of other medical illnesses [49-51]. Moreover, impairment in interpersonal and occupational life $[42,44,47]$, and early mortality and morbidity, as well as the impaired country economy, would happen [30, 52, 53] due to depression.

Pieces of the literature revealed that most of the world prisoners resides at low- and middle-income countries (LMICs) [15] including Ethiopia However, there existed 
a huge unmet need for treatment of mental illness in general [54-56] and depression in particular $[57,58]$ in prisoners and the general population as well. Such a gap in treatment for depression in Ethiopia should be addressed scientifically by supplementing concrete evidence about the burden of depression for policymakers and concerned stakeholders which would be helpful for sound decision making. Nevertheless, no previous systematic review and meta-analysis studies investigated the magnitude of depression in prisoner's population in Ethiopia. Therefore current systematic review and metaanalysis study aims to have a summary of pooled evidence in Ethiopia on the magnitude of depression in prisoner population and associated factors of depression in prisoner population as well as providing a recommendation for future researchers and other stakeholders.

\section{Methods}

The current systematic review and meta-analysis were adherent to the Preferred Reporting Items for Systematic Reviews and Meta-analysis Protocols (PRISMA-P) [59]. The PRISMA checklist is found in Additional file 1: PRISMA 2015 checklist.

\section{Data sources and search strategies}

A systematized search of PubMed with no time boundary, EMBASE, and Scopus databases were implemented under a detailed search strategy. We conducted our search in PubMed with the following key terms and words: (Prevalence OR epidemiology OR magnitude OR incidence) AND (depressive OR "depressive disorder" OR "depressive symptoms") AND (prisoner's OR inmates OR detainees OR incarcerated) AND (factor OR risk OR "risk factor" OR determinant) AND Ethiopia.

We used the conjunction "AND" to join the key terms above since our primary objective was to obtain studies that had assessed both depressive symptoms and the associated factors for depressive symptoms. Subjectspecific heading as recommended by database searches was used for Scopus and EMBASE searches. Furthermore, unpublished articles on WHO websites, nonindexed articles from Google scholar were investigated. Moreover, the reference lists of included studies were manually searched for additional eligible articles. We also contacted authors of the merged articles when further information was required.

\section{Inclusion criteria}

We were pre-planned to include cohort, case-control and cross-sectional studies which reported the magnitude of depressive symptoms and/or its associated factors in prisoners' population in Ethiopia. But, all of the studies obtained by stated search strategies were found to be a cross-sectional study. We designed and implemented on behalf of the following pre-specified inclusion criteria:

A. Cohort, case-control and cross-sectional studies.

B. Studies should be conducted on prisoners

C. Publication of articles should be in the English language

D. Articles that assessed Depression symptoms prevalence in prisoners

E. Articles that identified associated factors of depressive symptoms in prisoners

F. Studies must be conducted in Ethiopia

\section{Exclusion criteria}

A. Meta-analysis studies, experimental studies, commentaries, letters, and editorials were excluded.

B. Duplication studies were also checked and removed before the pooling process started.

\section{Selection of studies for inclusion in the review}

We authors of this review utilized the stated databases above to retrieve relevant articles that were stored for further management and use in an EndNote reference manager.

Three review authors (MN, AY, and MT) independently reviewed each study's title and abstracts from the EndNote reference manager and disagreements between these authors regarding the inclusion process were addressed through discussion and the fourth reviewer (YZ).

\section{Data extraction and management techniques}

A standardized form was used to extract data from the included studies; three review authors ( $M N, A B$, and MT) independently extracted data from included studies. The following parameters were utilized as components of a data extraction form and each of the authors extracting data use these parameters uniformly. The last name of the first author, publication year, study setting, sample size, number of individuals with depression, the magnitude of depression, assessment instruments, associated factors, and odds ratio (OR) with 95\% confidence intervals $(\mathrm{CI})$ were parameters used in extracting data from included studies.

\section{Quality assessment methods}

Two review authors (MN, YZ) independently assessed the quality of studies included in the analysis using the Newcastle-Ottawa Quality Assessment tool in its modified version [60]. Representativeness and size of the sample, comparability between study subjects, ascertainment of depressive symptoms, and statistical quality were the dimensions of the Newcastle-Ottawa scale in assessing 
the quality of each study. We take the average of two reviewers ( $\mathrm{MN}$ and $\mathrm{YZ}$ ) to determine the final quality score of that individual study and any disagreement between them was settled by a discussion with a third reviewer $(\mathrm{AB})$.

\section{Data synthesis and analysis}

The average magnitude of depression and the average OR of associated factors for depression with $95 \%$ CI was determined with random-effects [61] and quality-effects models [62]. We also employed Quality-effects metaanalysis to know how the quality of each study affects the average estimate compared with the results from random-effects meta-analysis. This analysis takes into consideration the quality score of individual studies in the estimation of the study weight.

Heterogeneity between the studies had been assessed with both Cochrane's Q statistic and the Higgins $\mathrm{I}^{2}$ test statistics which showed the variance between the included studies that were not due to a sampling error. In this review, a value of $\mathrm{I}^{2}$ statistics greater than $50 \%$ was used to detect the presence of heterogeneity between studies [63]. Since heterogeneity existed in the study, subgroup analyses and sensitivity analysis were performed to explore heterogeneity sources. Meta-XL version 5.3 [64] and STATA11 meta-prop packages [65] were used in the analysis. Publication bias was also assessed with funnel plot [66] and eggers publication bias test.

\section{Results}

\section{Identification of studies}

Our search for both published work and grey literature resulted in 232 documented papers. Among these 8 were identified unpublished works and the remaining 224 were published papers notified from the search through previously stated database searches. Of these records, 17 were excluded since they were duplicates and further 198 articles were excluded simply by reading their titles. The remaining 17 studies were fully assessed for eligibility but only 9 studies were incorporated in the final meta-analysis since the rest 8 studies were also excluded because of varieties of methodological and technical limitations (Fig. 1).

\section{Characteristics of included studies}

A total of 9 studies that assessed depressive symptoms in 3201 Ethiopian prisoners were incorporated into this

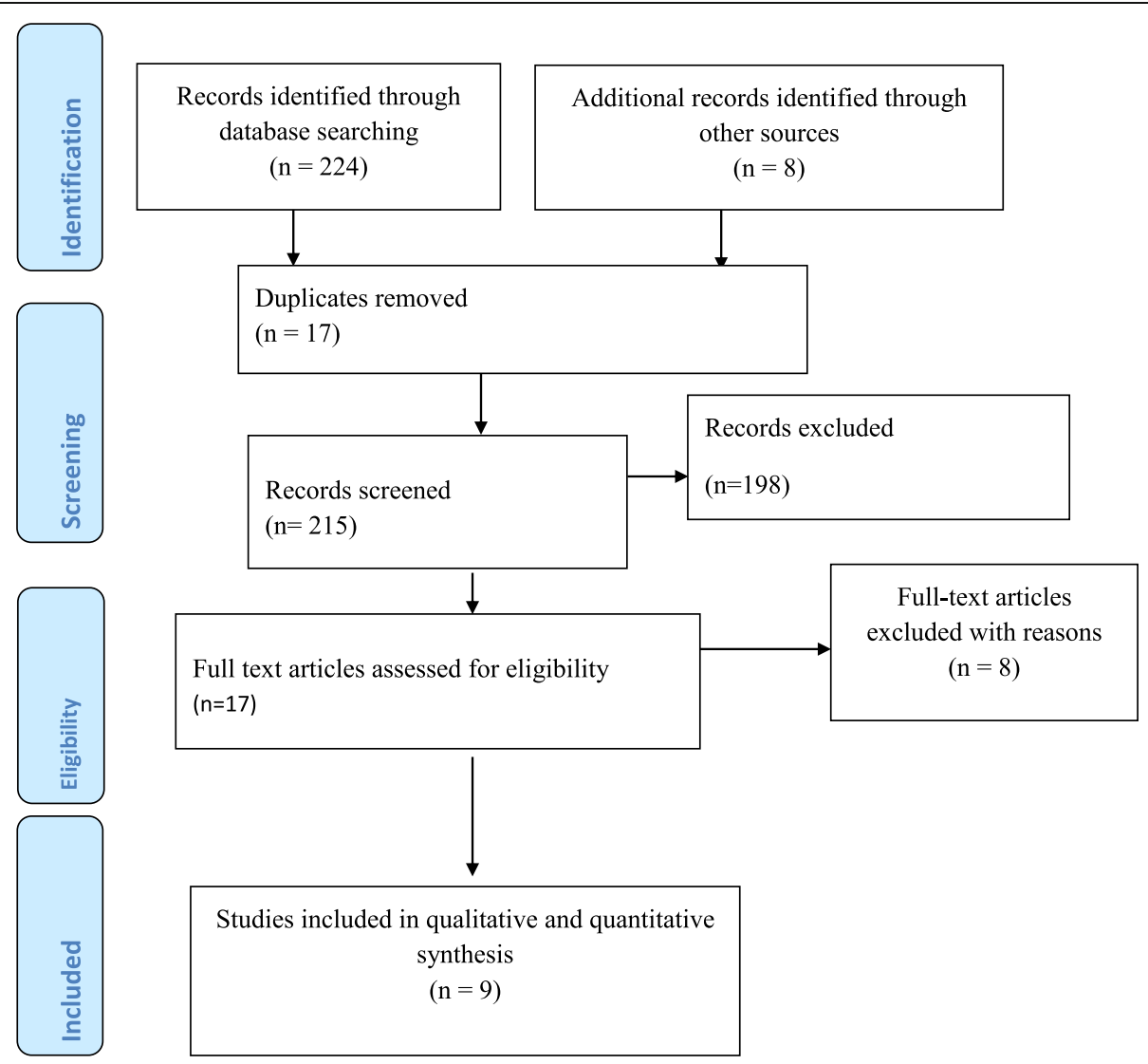

Fig. 1 PRISMA flow chart for the review search process 
review and meta-analysis study [10, 20-26, 28]. All included studies were institution based cross-sectional studies fulfilling the predefined inclusion criteria. One of these studies utilized a qualitative method (in-depth interview) of data gathering for associated factors of prisoner's depressive symptoms in addition to the quantitative method [24]. Of these included studies, three were from Amhara region, Ethiopia [20, 22, 25], two other studies were from Oromia region, southwest Ethiopia [10, 23], two studies were from Addis Ababa, central Ethiopia [26, 28] and last two studies were also from the southern part of the country [21, 24]. Four of the nine studies included in meta-analysis utilized BDIII $[10,23,24,28]$ for the assessment of depressive symptoms and the remaining five utilized PHQ-9 screening instruments $[20-22,25,26]$. Regarding the size of the sample utilized by the individual study three $[20,22,26]$ of the nine used a sample size of greater than 350 and the rest six $[10,21,23-25,28]$ have a sample size less than 350.

The sampling technique used in four of the studies $[20,21,25,26]$ was simple random sampling whereas another four studies utilized a systematic sampling method in recruiting their study subjects [10, 23, 24, 28]. The last one used a multi-stage sampling technique [22] (Table 1).

\section{Quality of included studies}

Generally, the overall score of quality assessment for the studies incorporated in the current meta-analysis varies from 6 to 10. Among the nine included studies, more than half (5 studies) had good quality and the rest 4 studies had moderate quality. None of the included studies were found to have poor quality (Additional file 2).

\section{The pooled prevalence of depressive symptoms in prisoners in Ethiopia}

Nine studies had reported the magnitude of depressive symptoms in prisoners in Ethiopia [10, 20-26, 28]. The reported magnitude of depressive symptoms among studies included in the current review and meta-analysis ranges from $41.9 \%[10,23]$ in two studies from Oromia, southwest Ethiopia to 89\% [24] in southern Ethiopia. The average prevalence of depressive symptoms among prisoners in Ethiopia using the random effect model ranges between 41.3 and $65.5 \%$. This pooled magnitude was having a significant heterogeneity $\left(\mathrm{I}^{2}=99.8 \%, p\right.$ value $<0.001)$ from the variation between the included studies (Fig. 2).

\section{Subgroup analysis of the prevalence of depressive symptoms in the prisoner's population in Ethiopia}

The result of a subgroup analysis based on the region from four areas of the country; Amhara region, [20, 22, 25], Oromia region [10, 23], Addis Ababa [26, 28] and Southern part of the country $[21,24]$ revealed that the pooled prevalence of Depressive symptoms in prisoners was $44.43,41.9,59.1$, and $72.7 \%$ respectively. Besides, the subgroup analysis of Depressive symptoms in prisoners concerning the assessment tool used implied that

Table 1 Characteristics of studies on depression in prisoners which are incorporated in the narrative as well as meta-analysis according to author first name, year of publication, setting of study, design, sample size, assessment instrument, study population and magnitude of depression

\begin{tabular}{|c|c|c|c|c|c|c|c|}
\hline Author, year & Location of prison & Study design & $\begin{array}{l}\text { Sample } \\
\text { size }\end{array}$ & $\begin{array}{l}\text { Tool (cutoff } \\
\text { point) }\end{array}$ & Study population & Depression(\%)(n) & $\begin{array}{l}\text { Sampling } \\
\text { Method }\end{array}$ \\
\hline $\begin{array}{l}\text { Alemayehu et al. } \\
2019 \text { [20] }\end{array}$ & $\begin{array}{l}\text { Amhara, northwest } \\
\text { Ethiopia }\end{array}$ & CS & 402 & PHQ-9( $\geq 5)$ & Prisoners & $45.5(n=183)$ & Simple random \\
\hline Reta et al. 2019 [25] & Amhara region & CS & 336 & PHQ-9(> 5) & Prisoners & $44(n=148)$ & Simple random \\
\hline Beyen et al. 2017 [22] & $\begin{array}{l}\text { Amhara, northwest } \\
\text { Ethiopia }\end{array}$ & CS & 649 & PHQ-9 & Prisoners & $43.8(n=284)$ & $\begin{array}{l}\text { Multi-stage- } \\
\text { random }\end{array}$ \\
\hline Abdu et al. 2018 [23]. & $\begin{array}{l}\text { Oromia, south west } \\
\text { Ethiopia }\end{array}$ & CS & 332 & BDI-II & Prisoners & $41.9(n=139)$ & $\begin{array}{l}\text { Systematic } \\
\text { sampling }\end{array}$ \\
\hline $\begin{array}{l}\text { Agegnew et al. } \\
2019 \text { [24] }\end{array}$ & Southern Ethiopia & CS & 327 & BDI-II & Prisoners & $89(n=291)$ & $\begin{array}{l}\text { Systematic } \\
\text { sampling }\end{array}$ \\
\hline $\begin{array}{l}\text { Bedaso et al. } \\
2018 \text { [21] }\end{array}$ & Southern Ethiopia & CS & 335 & PHQ-9( $\geq 5)$ & Prisoners & $56.4(n=189)$ & Simple random \\
\hline $\begin{array}{l}\text { Getaneh et al. } \\
2019 \text { [26] }\end{array}$ & $\begin{array}{l}\text { Addis Ababa, central } \\
\text { Ethiopia }\end{array}$ & CS & 400 & PHQ-9( $\geq 5)$ & $\begin{array}{l}\text { HIV-positive } \\
\text { prisoners }\end{array}$ & $66.5(n=266)$ & Simple random \\
\hline Tefera, 2018 [28] & $\begin{array}{l}\text { Addis Ababa, central } \\
\text { Ethiopia }\end{array}$ & $\begin{array}{l}\text { CS and } \\
\text { qualitative }\end{array}$ & 84 & BDI-II & Women inmates & $51.6(43)$ & $\begin{array}{l}\text { Systematic } \\
\text { sampling }\end{array}$ \\
\hline $\begin{array}{l}\text { Tirfeneh.et al. } \\
2018 \text { [10] }\end{array}$ & $\begin{array}{l}\text { Oromia, south west } \\
\text { Ethiopia }\end{array}$ & CS & 336 & $\mathrm{BDI}-\| \mathrm{I} \geq 14$ & prisoners & $41.9(141)$ & $\begin{array}{l}\text { Systematic } \\
\text { sampling }\end{array}$ \\
\hline
\end{tabular}

Key: BDI II: Beck depression inventory II, CS: Cross-sectional, HIV: Human Immune-Virus, PHQ-9: Patient Health Questionnaire-9 
Author, year of publication

$\%$

ES $(95 \% \mathrm{Cl}) \quad$ Weight

Alemayehu et al.2019

Beyene et al.2018

Abdu et al.2018

Bedaso et al.2018

Getaneh et al.2019

Reta et al.2019

Roba et al.2019

Tefera, 2019

Tirfeneh.et al 2018

Overall (I-squared $=99.80 \%, \mathrm{p}=0.000)$

NOTE: Weights are from random effects analysis

$-89.2$

0

89.2

Fig. 2 A forest plot for the prevalence of depression among prisoners in Ethiopia

Table 2 A subgroup analysis of the prevalence of depression among prisoners in Ethiopia based on random effect analysis

\begin{tabular}{|c|c|c|c|c|c|c|c|}
\hline \multirow[t]{2}{*}{ Subgroup } & & \multirow{2}{*}{$\begin{array}{l}\text { Number of } \\
\text { studies }\end{array}$} & \multicolumn{2}{|l|}{ Estimates } & \multicolumn{3}{|c|}{ Heterogeneity } \\
\hline & & & Prevalence (\%) & $95 \% \mathrm{Cl}$ & $1^{2}$ & $Q(D F)$ & $p$-value \\
\hline \multirow[t]{4}{*}{ Region } & Amhara & 3 & 44.43 & $43.36,45.550$ & $98.6 \%$ & $139.17(2)$ & $P<0.001$ \\
\hline & Oromia & 2 & 41.9 & $41.73,42.07$ & $0 \%$ & $0 \%(1)$ & $P=1.00$ \\
\hline & Southern part & 2 & 72.7 & $40.75,104.65$ & $99.8 \%$ & $3420(1)$ & $P<0.001$ \\
\hline & Addis Ababa & 2 & 59.05 & $44.45,73.65$ & $99.2 \%$ & $1246.23(1)$ & $P<0.001$ \\
\hline \multirow[t]{2}{*}{ Tools } & PHQ-9 & 5 & 51.24 & $42.23,60.25$ & $98.8 \%$ & $921.57(4)$ & $P<0.001$ \\
\hline & $\mathrm{BDI}-\mathrm{II}$ & 4 & 56.15 & $29.09,83.11$ & $99.6 \%$ & $1742.86(3)$ & $P<0.001$ \\
\hline \multirow[t]{2}{*}{ Sample } & $<350$ & 6 & 54.13 & $35.66,72.60$ & $99.2 \%$ & $1242.12(5)$ & $P<0.001$ \\
\hline & $\geq 350$ & 3 & 51.93 & $38.08,65.78$ & $98.8 \%$ & $935.75(2)$ & $P<0.001$ \\
\hline \multirow[t]{2}{*}{ Sampling technique } & Simple random & 4 & 53.1 & $42.23,63.97$ & $99 \%$ & $1150.75(3)$ & $P<0.001$ \\
\hline & Systematic and multi-stage & 5 & 53.64 & $33.15,74.13$ & $99.4 \%$ & $1624.13(4)$ & $P<0.001$ \\
\hline
\end{tabular}

Key: BDI II Beck depression inventory II, DF Degree of Freedom, PHQ-9 Patient Health Questionnaire-9 
the pooled depressive symptom prevalence among prisoners as measured with PHQ-9 was found to be $51.2 \%$ whereas it is 56.2 in those studies which assessed depression with BDI-II. Besides, studies that utilized a relatively large sample size $(\geq 350)[20,22,26]$ yields a smaller pooled prevalence of depression, 51.93 than those studies which utilized smaller sample size $(<350)[10,21$, $23-25,28]$ in which the average prevalence was 54.1 (Table 2).

\section{Sensitivity analysis}

For further investigation of the source of heterogeneity in the analysis of the prevalence of depressive symptoms in prisoners, we performed a leave-one-out sensitivity analysis. Our sensitivity analysis result showed that the point estimated prevalence obtained when each study is left out from analysis was inside the confidence interval of the pooled depressive symptom prevalence. Therefore, the result of the pooled magnitude of depressive symptoms in prisoners can be plausible. The one study leave out at a time analysis showed that the pooled depressive symptoms prevalence ranges between $48.9(42.69,55.21)$ and $54.8(41.72,67.95)$ after the omission of a single study (Table 3 ).

\section{Publication Bias}

The egger's publication bias plot is around the origin and Egger's regression tests $(P=0.785)$ provided then no significant publication bias for the prevalence of depressive symptoms in prisoners in Ethiopia. Also, a funnel plot for a Logit event rate of prevalence of depressive symptoms in prisoners against its standard error strengthened this (Fig. 3).

Factors associated with depression in Ethiopian prisoners Among 9 studies included 7 studies that conveyed the factors associated with depressive symptoms in prisoner's population in Ethiopia were incorporated in the qualitative analysis for associated factors of prisoner's depressive symptoms [20-23, 25, 26, 28] (See Table 4). Association between comorbidity of medical illness in prisoners was a contributing factor for prisoner's Depressive symptoms in four of the included studies [21, $23,25,26]$. Besides, narrative review of the factors illustrated that longer duration of the sentence was found to have an association with the development of depressive symptoms in prison $[20,25,26]$, poor social support was also noticed to be a contributing factor for depressive symptoms in two of the included studies [22, 23]. Moreover, a family history of mental illness, previous incarceration and lifetime alcohol use [23], a suicidal attempt and ever-faced stressful event [25] were some of the mentioned factors.

Considering the strength of association; health satisfaction rated as moderate, being sentenced for 1-5 years [20], having a plan to commit suicide [22], having a family history of mental illness, having a history of previous incarceration, lack of job in the prison, lifetime alcohol use [23], primary level of education and perceived stigma, long stay in prison $\geq 10$ years [26], being widowed, educated at college or university level and having a chronic medical illness [25] had a strong and positive association with depression in Ethiopian prisoners (Table 4).

\section{Discussion}

To the investigator's knowledge, this review and metaanalysis on the prevalence of depression and the associated factors in individuals at the prison setting are the first of its type in Ethiopia in this target population. Therefore, the knowledge generated from this metaanalysis on pooled magnitude and risk factors for depression at prisoners of Ethiopia will be important evidence to different stakeholders intending to design policy in the area.

The result of the meta-analysis showed that depression in the prisoners in Ethiopia was high (53.40\%). This high

Table 3 A sensitivity analysis of the prevalence of depression in Ethiopian prisoners when each indicated studies are removed at a time with its 95\% confidence interval

\begin{tabular}{llll}
\hline No & Study excluded & Prevalence of depression & 95\% Confidence interval \\
\hline 1 & Alemayehu et al. 2019 [20] & 54.39 & $40.95,67.83$ \\
2 & Beyen et al. 2017 [22] & 54.60 & $40.85,68.35$ \\
3 & Abdu et al. 2018 [23] & 54.84 & $41.72,67.95$ \\
4 & Bedaso et al. 2018 [21] & 53.03 & $39.63,66.42$ \\
5 & Getaneh et al. 2019 [26] & 51.76 & $38.42,65.10$ \\
6 & Reta et al. 2019 [25] & 54.58 & $41.37,67.78$ \\
7 & Agegnew et al. 2019 [24] & 48.95 & $42.69,55.21$ \\
8 & Tefera, 2018 [28] & 53.63 & $40.56,66.69$ \\
\end{tabular}




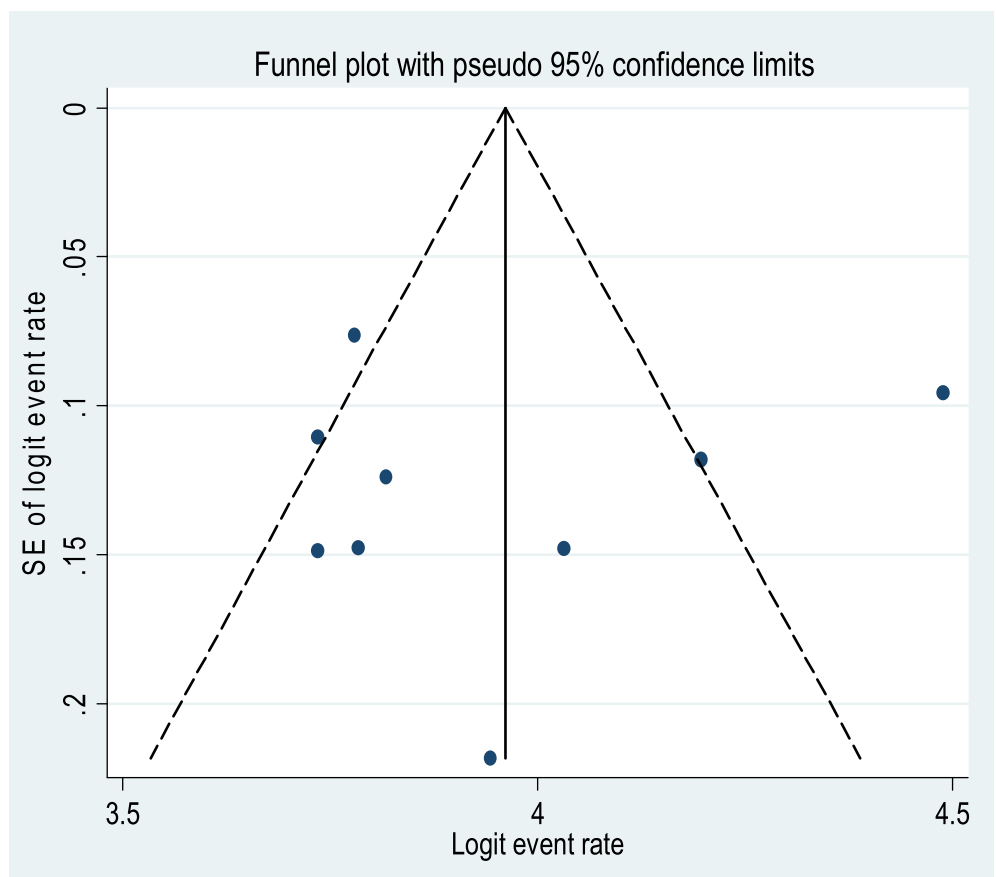

Fig. 3 Funnel plot of the risk of publication bias for the prevalence of depression in prisoners

pooled result revealed that depression in prisoners is an important public health problem.

In the current review and meta-analysis, the existing available information varies by a region where the study was conducted, data collection instrument used to screen depression, the sample size incorporated in the study and sampling technique employed in data collection. More than half $(n=5)$ of the incorporated studies utilized PHQ-9 to screen depression whereas the rest utilized BDI-II. Two-third of the included studies utilized a sample size of less than 350 .

In this meta-analysis, the pooled depression prevalence among prisoners in Ethiopia (53.4\%) was Larger than an Iranian review and meta-analysis study on 1708 prisoners and 12 articles in which a pooled magnitude of depression was $42 \%$ [14] and also another meta-analysis that reported $10 \%$ of males and $12 \%$ of female worldwide prisoners as having depression [8]. The reason for such a high magnitude in the Ethiopian context would be due to the poor setting of prison and poor health care coverage, poor fulfillment of basic human needs. Moreover, differences in administrative procedures in the prison setting and variation in constitutional affairs across such countries could bring the discrepancy. Besides, variation in socio-cultural and environmental factors should be taken into consideration.

Besides, this result was also bigger than a nationallevel estimate of depression in Ethiopia which was reported to be from 9.1 to $11 \%$ [27, 29]. Moreover, another review and meta-analysis of depression in the Ethiopian community found that a pooled depression prevalence of $20.5 \%$ [30] which was also lower when compared to the current finding. This variance could happen because of denial of liberty due to imprisonment resulting in a denial of choices usually reserved for the outside community $[67,68]$. Moreover, external factors such as overcrowded living conditions, poor quality of life, poor living environment as well as Internal factors such as a guilty feeling of the offenses committed, stigmatization $[67,69]$ could cause the magnitude of depression in the prison to be higher as compared to the community.

A considerable regional variation on the pooled magnitude of depression in prisoners was observed in this review and meta-analysis study. An apparent difference in the pooled prevalence of depression ranges from as low as $41.9 \%$ in the Oromia region to $72.9 \%$ in southern Ethiopia. The difference in factors related to the prison setting and administrative procedures for handling the mechanism of prisoners across the regions would be considered as possible justifications. Variation in the detection instrument used such as PHQ-9 for studies in the Amhara region, BDI-II in Oromia region and both PHQ-9 and BDI-II in southern regions might also cause such difference. Moreover, variation in cultural, economic and environmental conditions could also be responsible for such discrepancy.

Regarding the variation of the pooled magnitude of depression across measurement instruments, the average 
Table 4 Characteristics of associated factors for depression in prisoners in Ethiopia by their Odds ratio, Confidence interval, association strength, author and year of publication

\begin{tabular}{|c|c|c|c|c|}
\hline Associated factors & Odds ratio(AOR) & $95 \% \mathrm{Cl}$ & Strength of association & Author, year of publication \\
\hline Having children & 2.48 & $1.60,3.83$ & Moderate, positive & Alemayehu et al.,2019 [20] \\
\hline Health satisfaction rated as moderate & 3.2 & $1.12,9.00$ & Strong and positive & Alemayehu et al. 2019 [20] \\
\hline Health satisfaction rated as dissatisfied & 1.63 & $1.02,2.62$ & Moderate, positive & Alemayehu et al. 2019 [20] \\
\hline Being sentenced for more than 5 years & 2.31 & $1.01,5.25$ & Moderate, positive & Alemayehu et al. 2019 [20] \\
\hline Being sentenced for $1-5$ years & 3.04 & $1.20,7.71$ & Strong and positive & Alemayehu et al. 2019 [20] \\
\hline Not satisfied with day to day life before imprisonment & 0.44 & $0.26,0.63$ & Moderate, negative & Beyen et al. 2017 [22] \\
\hline Thought of facing difficulty to run life as before after release & 1.87 & $1.3,2.69$ & Moderate, positive & Beyen et al. 2017 [22] \\
\hline Having a plan to commit suicide & 4.16 & $2.56,6.77$ & Strong and positive & Beyen et al. 2017 [22] \\
\hline Good social support & 0.62 & $0.44,0.89$ & Strong and negative & Beyen et al. 2017 [22] \\
\hline Prison setting being at Gondar & 1.54 & $1.04,2.29$ & Moderate, positive & Beyen et al. 2017 [22] \\
\hline Prison setting being at Debre-tabor & 2.27 & $1.46,3.51$ & Moderate, positive & Beyen et al. 2017 [22] \\
\hline Having family history of mental illness & 6.05 & $2.60,13.8$ & Strong and positive & Abdu et al. 2018 [23] \\
\hline Having chronic physical illness & 2.87 & $1.29,6.41$ & Moderate, positive & Abdu et al. 2018 [23] \\
\hline Having history of previous incarceration & 3.26 & $1.02,10.64$ & Strong and positive & Abdu et al. 2018 [23] \\
\hline Lack of job in the prison & 4.96 & $2.09,11.8$ & Strong and positive & Abdu et al. 2018 [23] \\
\hline Lifetime alcohol use & 3.61 & $1.80,7.26$ & Strong and positive & Abdu et al. 2018 [23] \\
\hline Thinking life to be a difficult one after release from prison & 2.07 & $1.20,3.60$ & Moderate, positive & Abdu et al. 2018 [23] \\
\hline Having age between 21 and 25 years & 2.04 & $1.06,3.89$ & Moderate, positive & Abdu et al. 2018 [23] \\
\hline Poor social support & 2.2 & $1.27,3.82$ & Moderate, positive & Abdu et al. 2018 [23] \\
\hline Primary education & 4.17 & $1.65,10.48$ & Strong and positive & Getaneh et al. 2019 [26] \\
\hline Perceived stigma & 3.88 & $2.08,7.25$ & Strong and positive & Getaneh et al. 2019 [26] \\
\hline History of chronic illness & 2.88 & $1.34,6.17$ & Moderate, positive & Getaneh et al. 2019 [26] \\
\hline WHO clinical stage II AIDS & 2.47 & $1.19,5.12$ & Moderate, positive & Getaneh et al. 2019 [26] \\
\hline Length of stay in prison 4-6 years & 2.27 & $1.22,4.23$ & Moderate, positive & Getaneh et al. 2019 [26] \\
\hline Length of stay in prison $\geq 10$ years & 3.5 & $1.15,10.85$ & Strong and positive & Getaneh et al. 2019 [26] \\
\hline Not participating in IGA inside the prison & 0.53 & $0.32,0.87$ & Moderate, negative & Bedaso et al. 2018 [21] \\
\hline Having chronic disease & 2.62 & $1.29,5.32$ & Moderate, positive & Bedaso et al. 2018 [21] \\
\hline History of Chat chewing & 2.47 & $1.04,5.85$ & Moderate, positive & Bedaso et al. 2018 [21] \\
\hline Widowed & 6.3 & $1.09,36.67$ & Strong and positive & Reta et al. 2019 [25] \\
\hline Educated at college or university level & 5.34 & $1.59,17.94$ & Strong and positive & Reta et al. 2019 [25] \\
\hline A history of suicidal attempt & 2.76 & $1.04,7.31$ & Moderate, positive & Reta et al. 2019 [25] \\
\hline Ever faced a severe stressful life event & 2.57 & $1.41,4.67$ & Moderate, positive & Reta et al. 2019 [25] \\
\hline $5-10$ years of sentence & 2.5 & $1.32,4.79$ & Moderate, positive & Reta et al. 2019 [25] \\
\hline Having chronic medical illness & 3.32 & $1.26,8.75$ & Strong and positive & Reta et al. 2019 [25] \\
\hline
\end{tabular}

IGA Income Generating Activities

WHO World Health Organization

AIDS Acquired Immune Deficiency Syndrome

magnitude of depression as measured by Beck depression inventory-II (BDI-II) was higher (56.15\%) than the average magnitude obtained when studies that assessed depression with PHQ-9 was pooled (51.25\%). This might happened because studies included in the current metaanalysis and that utilized PHQ-9 depression screening instrument $[20,22,26]$ incorporated a relatively larger sample size as compared to those studies which utilized beck depression inventory-II and it is statistically obvious that adequate sample size will lead to a precise and accurate result.

Moreover, the slightly lower pooled prevalence of depression in prisoners was observed in studies that utilized a sample size greater than 350 (51.93\%) than the pooled magnitude of depression in prisoners that used a sample size less than 350 participants (54.13\%). The 
reason could be a larger sample size decreases the probability of a standard error thereby providing a more precise and reliable result with strong power despite the cost to time and money.

Regarding the associated factors, a narrative review of a factor in this review illustrated that factors like health satisfaction rated as moderate, being sentenced for 1-5 years, having a plan to commit suicide, having a family history of mental illness, having a history of the previous incarceration, lack of job in the prison, lifetime alcohol use, primary level of education and perceived stigma, long stay in prison $\geq 10$ years, being widowed, educated at college or university level and having chronic medical illness were found to had a strong and positive association with depression in Ethiopian prisoners.

\section{Difference between studies incorporated in the current review and meta-analysis study}

This meta-analysis study was obtained to have a high degree of heterogeneity between the studies incorporated in pooling the prevalence of depression at prisoners of Ethiopia. The analysis of subgroups for detection of sources of heterogeneity was done and region of the country where the study was done, data collection tools and sample size were identified to contribute to the existing variation between the studies incorporated in the analysis. Moreover, we performed one study leave out at a time sensitivity analysis to explore further the impact of a single study on the overall estimate: whether a particular study included in the pooled effect size for depression in prisoners in Ethiopia was influential but our analysis showed that the heterogeneity between the nine included studies in the pooled prevalence was not influenced by a single particular study.

This study has limitations such as a small number of studies incorporated in the subgroup analysis that might minimize the estimate precision. Besides, the presence of heterogeneity in the pooled effect size was also the second limitation. Moreover, we describe the associated factors for prisoner's depression only qualitatively since studies included did not report a consistent effect size for it.

\section{Conclusion}

This review and meta-analysis study obtained a pooled magnitude of depression in prisoner's population in Ethiopia to be very high, $53.40 \%(95 \%$ CI: $41.33,65.46)$ and this pooled estimate was under the influence of considerable heterogeneity. Our, subgroup analysis showed that the pooled effect size for the depression prevalence was significantly in the southern region of the country than the pooled magnitude of depression in Oromia, southwest Ethiopia. Besides, the pooled prevalence of depression in Ethiopian prisoners was significantly higher as measured by the Beck Depression Inventory-II tool than the pooled prevalence obtained by the patient health questionnaire. Moreover, studies that utilized a slightly larger sample size $(\geq 350)$ when pooled provided a significantly lower pooled magnitude of depression among prisoners in Ethiopia than the pooled prevalence of depression obtained when studies which utilized smaller sample size $(<350)$. This pooled effect size of depression in the prisoner's population in Ethiopia obtained is very important as it showed aggregated evidence of the burden of depression in the targeted population which would be an important figure for further interventional activities in the area. Special consideration should be given to prisoners with a family history of mental illness, having a history of the previous incarceration, lack of job in the prison, lifetime alcohol use, primary level of education and perceived stigma, long stay in prison $\geq 10$ years and having a chronic medical illness. This study would therefore be important for health care interventions for depression of prisoners and the associated factors mentioned above.

\section{Supplementary information}

Supplementary information accompanies this paper at https://doi.org/10. 1186/s12888-020-02662-5.

Additional file 1. PRISMA-P 2015 Checklist.

Additional file 2. Quality assessment result of the studies included in this meta-analysis.

\section{Abbreviations}

BDI-II: Beck Depression Inventory; Cl: Confidence Interval; ICD10: International Classification for Diseases-10; LMICs: Low and MiddleIncome Countries; OR: Odds Ratio; PHQ-9: Patient Health Questionnaire-9; PRISMA-P: Preferred Reporting Items for Systematic Reviews and Metaanalysis; WHO: World Health Organization

\section{Acknowledgments}

None.

Authors' contributions

MN designed the review idea on the magnitude and associated factors of depression in prisoners and outlined the search strategies and does the analysis of the research. $M N, A B$, and $M T$ extract the data from included studies. $M N, A B$, and $Y Z$ assessed the quality of included studies. MN writes the manuscript first draft. All authors reviewed the final version of the review manuscript and approved it.

Funding

We authors have no funding source for this review work.

Availability of data and materials

All data regarding this research work is incorporated in the paper.

Ethics approval and consent to participate

Not applicable.

Consent for publication

Not Applicable.

Competing interests

No competing interests existed for this work. 


\section{Received: 6 January 2020 Accepted: 11 May 2020}

Published online: 05 June 2020

\section{References}

1. Haidar J, Melaku U, Pobocik R. Folate deficiency in women of reproductive age in nine administrative regions of Ethiopia: an emerging public health problem. South Afr J Clin Nutr. 2010;23(3):132-7.

2. World health organization. The World Health Report 2001: Mental health: new understanding, new hope. Geneva: World Health Organization; 2001.

3. World health organization. ECOSOC meeting addressing noncommunicable diseases and mental health: major challenges to sustainable development in the 21st century: World Health Organization; 2009. p. 1-32.

4. Brink J. Epidemiology of mental illness in a correctional system. Curr Opin Psychiatry. 2005;18(5):536-41.

5. Falissard B, Loze J-Y, Gasquet I, Duburc A, De Beaurepaire C, Fagnani F, et al. Prevalence of mental disorders in French prisons for men. BMC Psychiatry. 2006;6(1):33

6. World health organization. Background paper for trencín statement on prisons and mental health. Slovakia: WHO Publication; 2008

7. Blaauw E, Roesch R, Kerkhof A. Mental disorders in European prison systems: arrangements for mentally disordered prisoners in the prison systems of 13 European countries. Int J Law Psychiatry. 2000;23(5-6):649-63.

8. Fazel S, Seewald K. Severe mental illness in 33588 prisoners worldwide: systematic review and meta-regression analysis. Br J Psychiatry. 2012;200(5): 364-73.

9. Dadi AF, Dachew BA, Kisi T, Yigzaw N, Azale T. Anxiety and associated factors among prisoners in north west of Amhara regional state, Ethiopia. BMC Psychiatry. 2016;16(1):83.

10. Tirfeneh E, Abera M, Yeshigeta E, Mamaru A, Dube L, Srahbzu M. Suicidal Behavior and Associated Factors among Prisoners in Jimma Town Correctional Institution South, West Ethiopia, 2017; 2018.

11. Solomon A, Mihretie G, Tesfaw G. The prevalence and correlates of common mental disorders among prisoners in Addis Ababa: an institution based cross-sectional study. BMC Res Notes. 2019;12(1):394.

12. Yitayih Y, Abera M, Tesfaye E, Mamaru A, Soboka M, Adorjan K. Substance use disorder and associated factors among prisoners in a correctional institution in Jimma, Southwest Ethiopia: a cross-sectional study. BMC Psychiatry. 2018;18(1):314

13. Brugha $T$, Singleton $N$, Meltzer $H$, Bebbington $P$, Farrell $M$, Jenkins $R$, et al. Psychosis in the community and in prisons: a report from the British National Survey of psychiatric morbidity. Am J Psychiatr. 2005;162(4):774-80.

14. Valizadeh R, Veisani Y, Delpisheh A, Kikhavani S, Sohrabnejad A. Major depression and psychiatric disorders in Iranian prisoners based on a clinical interview: a systematic review and meta-analysis. Shiraz E-Med J. 2017;18(6): e44979

15. Værøy H. Depression, anxiety, and history of substance abuse among Norwegian inmates in preventive detention: reasons to worry? BMC Psychiatry. 2011;11(1):40.

16. Minhat $\mathrm{H}$. Prevalence and Socio-demographic Determinants of Depression among Inmates of a Prison in Malaysia. Online J Health Allied Sci. 2019; 18(2):4. https://www.ojhas.org/issue70/2019-2-4.html.

17. Mundt AP, Alvarado R, Fritsch R, Poblete C, Villagra C, Kastner S, et al. Prevalence rates of mental disorders in Chilean prisons. PLoS One. 2013:8(7): e69109.

18. Shahid I, Aftab MA, Yousaf Z, Naqvi SH, Hashmi AM. Prevalence of depression among male prisoners at an urban jail in Pakistan. HealthMED. 2014;8:699.

19. Majekodunmi OE, Obadeji A, Oluwole LO, Oyelami RO. Depression in prison population: demographic and clinical predictors. J Forensic Sci Med. 2017; 3(3):122.

20. Alemayehu F, Ambaw F, Gutema H. Depression and associated factors among prisoners in Bahir Dar prison. Ethiopia BMC Psychiatry. 2019;19(1):88.

21. Bedaso A, Kediro G, Yeneabat T. Factors associated with depression among prisoners in southern Ethiopia: a cross-sectional study. BMC Res Notes. 2018; 11(1):637.

22. Beyen TK, Dadi AF, Dachew BA, Muluneh NY, Bisetegn TA. More than eight in every nineteen inmates were living with depression at prisons of Northwest Amhara regional state, Ethiopia, a cross sectional study design. BMC Psychiatry. 2017;17(1):31

23. Abdu Z, Kabeta T, Dube L, Tessema W, Abera M. Prevalence and associated factors of depression among prisoners in Jimma Town Prison, South West
Ethiopia. Psychiatry J. 2018;10. Article ID 5762608. https://doi.org/10.1155/ 2018/5762608

24. Agegnew GR, Mohammed AH, Worku BN. Symptoms and underlying factors of Depression among inmates in Bonga town correctional center, Kaffa zone, SNNPR, Ethiopia. Int J Multicultural Multireligious Underst. 2019; 6(4):505-21.

25. Reta Y, Getachew R, Bahiru M, Kale B, Workie K. Depressive disorder and its associated factors among prisoners in Debre Berhan town, north Showa, Ethiopia. BioRxiv. 2019;703223. https://doi.org/10.1101/ 703223.

26. Getaneh M, Reta MM, Assefa D, Yohannis Z, Demilew D. Two-third of inmates were depressed among HIV positive prisoners at central prison (Kaliti), Addis Ababa, Ethiopia. BMC Res Notes. 2019;12(1):170.

27. Bitew T. Prevalence and risk factors of depression in Ethiopia: a review. Ethiop J Health Sci. 2014:24(2):161-9.

28. Tefera T. Depression Among Women Offenders in Kality Correctional Center Addis Ababa: Prevalence and Contributing Factors: Addis Abeba University Ethiopia. 2018. Addis Ababa University Institutional data repository.

29. Hailemariam S, Tessema F, Asefa M, Tadesse H, Tenkolu G. The prevalence of depression and associated factors in Ethiopia: findings from the National Health Survey. Int J Ment Heal Syst. 2012;6(1):23.

30. Bifftu BB, Takele WW, Guracho YD, Yehualashet FA. Depression and its help seeking behaviors: a systematic review and meta-analysis of community survey in Ethiopia. Depress Res Treat. 2018;2018:11. Article ID 1592596. https://doi.org/10.1155/2018/1592596.

31. Rao G, Manaf RA, Minhat HS. A review on determinants of Depression among adult prisoner. Malays J Med Health Sci. 2015;14(2):75-87.

32. Singleton N, Meltzer H. "Serious mental disorder in 23,000 prisoners: A systematic review of 62 surveys": Comment. Lancet. 2002;360(9332):572-3 https://doi.org/10.1016/S0140-6736(02)09727-1.

33. Andreoli SB, dos Santos MM, Quintana MI, Ribeiro WS, Blay SL, Taborda JGV, et al. Prevalence of mental disorders among prisoners in the state of Sao Paulo, Brazil. PLoS One. 2014;9(2):e88836.

34. Constantino P, Gonçalves de Assis S, Wernersbach Pinto L. The impact of prisons on the mental health of prisoners in the state of Rio de Janeiro, Brazil. Rev Ciênc Saúde Colet. 2016:21(7):2089-100.

35. Ahmad A, Mazlan NH. Stress and depression: a comparison study between men and women inmates in peninsular Malaysia. Int J Humanit Soc Sci. 2014:4(2):153-60.

36. Datta PV, Vijaya M, Krishna I, Bai BS, Sharon M, Ramam S, et al. Indo Am J Pharma Res. 2015;5(9):2893-8.

37. Nwaopara U, Stanley P. Prevalence of depression in Port Harcourt prison. J Psychiatry. 2015;18(340):2.

38. Aishatu Y, Armiya U, Obembe A, Moses DA, Tolulope OA. Prevalence of psychiatric morbidity among inmates in Jos maximum security prison. 2013; 3(1):12-7.

39. Rowell TL, Draine J, Wu E. Depression in a random sample of incarcerated African-American men. Psychiatr Serv. 2011;62(1):103-4

40. El-Gilany A, Khater M, Gomaa Z, Hussein E, Hamdy I. Psychiatric disorders among prisoners: a national study in Egypt. East Asian Arch Psychiatr. 2016; 26(1):30.

41. Uche N, Princewill S. Clinical factors as predictors of depression in a Nigerian prison population. J Psychiatry. 2015;14(02):75-87.

42. Misganaw A, Melaku YA, Tessema GA, Deribew A, Deribe K, Abera SF, et al. National disability-adjusted life years (DALYs) for 257 diseases and injuries in Ethiopia, 1990-2015: findings from the global burden of disease study 2015. Popul Health Metrics. 2017:15(1):28.

43. Mossie A, Kindu D, Negash A. Prevalence and severity of depression and its association with substance use in Jimma town, Southwest Ethiopia. Depress Res Treat. 2016;2016:3460462/7. https://doi.org/10. $1155 / 2016 / 3460462$

44. Duko B, Ayano G. Suicidal ideation and attempts among people with severe mental disorder, Addis Ababa, Ethiopia, comparative cross-sectional study. Ann General Psychiatry. 2018:17(1):23.

45. Fekadu A, Medhin G, Selamu M, Shiferaw T, Hailemariam M, Rathod SD, et al. Non-fatal suicidal behaviour in rural Ethiopia: a cross-sectional facility-and population-based study. BMC Psychiatry. 2016;16(1):75.

46. Shibre T, Hanlon C, Medhin G, Alem A, Kebede D, Teferra S, et al. Suicide and suicide attempts in people with severe mental disorders in Butajira, Ethiopia: 10 year follow-up of a population-based cohort. BMC Psychiatry. 2014;14(1):150. 
47. Reddy M. Depression: the disorder and the burden. Indian J Psychol Med. 2010;32(1):1.

48. Srinivasan K, Isaacs A, Villanueva E, Lucas A, Raghunath D. Medical attribution of common mental disorders in a rural Indian population. Asian J Psychiatr. 2010;3(3):142-4.

49. Duko B, Gebeyehu A, Ayano G. Prevalence and correlates of depression and anxiety among patients with tuberculosis at WolaitaSodo University hospital and Sodo health center, WolaitaSodo, South Ethiopia, cross sectional study. BMC Psychiatry. 2015;15(1):214.

50. Ambaw F, Mayston R, Hanlon C, Alem A. Depression among patients with tuberculosis: determinants, course and impact on pathways to care and treatment outcomes in a primary care setting in southern Ethiopia-a study protocol. BMJ Open. 2015;5(7):e007653.

51. Dejenie, Habtewold T, Radie YT, Sharew NT. Prevalence of depression among type 2 diabetic outpatients in black lion general specialized hospital, Addis Ababa, Ethiopia. Depress Res Treat. 2015;2015:184902/8. https://doi. org/10.1155/2015/184902.

52. Depression W. Other common mental disorders: Global Health estimates. Geneva: World Health Organization; 2017. p. 1-24.

53. Jordans M, Rathod S, Fekadu A, Medhin G, Kigozi F, Kohrt B, et al. Suicidal ideation and behaviour among community and health care seeking populations in five low-and middle-income countries: a cross-sectional study. Epidemiol Psychiatric Sci. 2018;27(4):393-402.

54. Dagnew M-B. Pattern of health care utilisation in a small rural Ethiopian town. Ethiop Med J. 1984;22(4):173-7.

55. Girma E, Tesfaye M. Patterns of treatment seeking behavior for mental illnesses in Southwest Ethiopia: a hospital based study. BMC Psychiatry. 2011;11(1):138

56. Bekele YY, Flisher A, Alem A, Baheretebeb Y. Pathways to psychiatric care in Ethiopia. Psychol Med. 2009;39(3):475-83.

57. Fekadu A, Alem A, Medhin G, Shibre T, Cleare A, Prince M, et al. Utility of the concept of minor depressive disorder: evidence from a large rural community sample in a developing country setting. J Affect Disord. 2007; 104(1-3):111-8.

58. Rathod SD, De Silva MJ, Ssebunnya J, Breuer E, Murhar V, Luitel NP, et al. Treatment contact coverage for probable depressive and probable alcohol use disorders in four low-and middle-income country districts: the PRIME cross-sectional community surveys. PLoS One. 2016;11(9):e0162038.

59. Moher D, Shamseer L, Clarke M, Ghersi D, Liberati A, Petticrew M, et al. Preferred reporting items for systematic review and meta-analysis protocols (PRISMA-P) 2015 statement. Syst Rev. 2015;4(1):1.

60. Stang A. Critical evaluation of the Newcastle-Ottawa scale for the assessment of the quality of nonrandomized studies in meta-analyses. Eur J Epidemiol. 2010;25(9):603-5.

61. Berkey CS, Hoaglin DC, Mosteller F, Colditz GA. A random-effects regression model for meta-analysis. Stat Med. 1995;14(4):395-411.

62. Doi SA, Thalib L. A quality-effects model for meta-analysis. Epidemiology. 2008;19(1):94-100.

63. Higgins JP, Thompson SG. Quantifying heterogeneity in a meta-analysis. Stat Med. 2002:21(11):1539-58.

64. Barendregt JJ, Doi SA. MetaXL user guide. Version. 2016;4:2011-6.

65. Nyaga VN, Arbyn M, Aerts M. Metaprop: a Stata command to perform metaanalysis of binomial data. Arch Public Health. 2014;72(1):39.

66. Liu JL. The role of the funnel plot in detecting publication and related biases in meta-analysis. Evid Based Dentistry. 2011;12(4):121.

67. Møller L, Gatherer A, Jürgens R, Stöver H, Nikogosian H. Health in prisons: a WHO guide to the essentials in prison health. Geneva: WHO regional office Europe; 2007.

68. Crafts N, Fearon P. The great depression of the 1930s: lessons for today. Oxford: Oxford University press; 2013.

69. Kupers TA, Toch H. Prison madness: the mental health crisis behind bars and what we must do about it. San Francisco: Jossey-Bass; 1999.

\section{Publisher's Note}

Springer Nature remains neutral with regard to jurisdictional claims in published maps and institutional affiliations.

\section{Ready to submit your research? Choose BMC and benefit from}

- fast, convenient online submission

- thorough peer review by experienced researchers in your field

- rapid publication on acceptance

- support for research data, including large and complex data types

- gold Open Access which fosters wider collaboration and increased citations

- maximum visibility for your research: over $100 \mathrm{M}$ website views per year

At BMC, research is always in progress.

Learn more biomedcentral.com/submissions 